\title{
Real-World Experience in Toxicity with Bevacizumab in Indian Cancer Patients
}

\author{
Pratik P. Patil ${ }^{1}$ Ranga R. Rangaraju ${ }^{1}$ Waseem Abbas ${ }^{1}$ Sunny Garg ${ }^{1}$
}

${ }^{1}$ Department of Medical Oncology, Max Super Specilaity Hospital,

Address for correspondence Pratik P. Patil, Department of Medical New Delhi, India

Oncology, Max Super Specilaity Hospital, New Delhi 110017, India (e-mail: pratikpatil79@rediffmail.com).

South Asian J Cancer 2021;10:131-134.

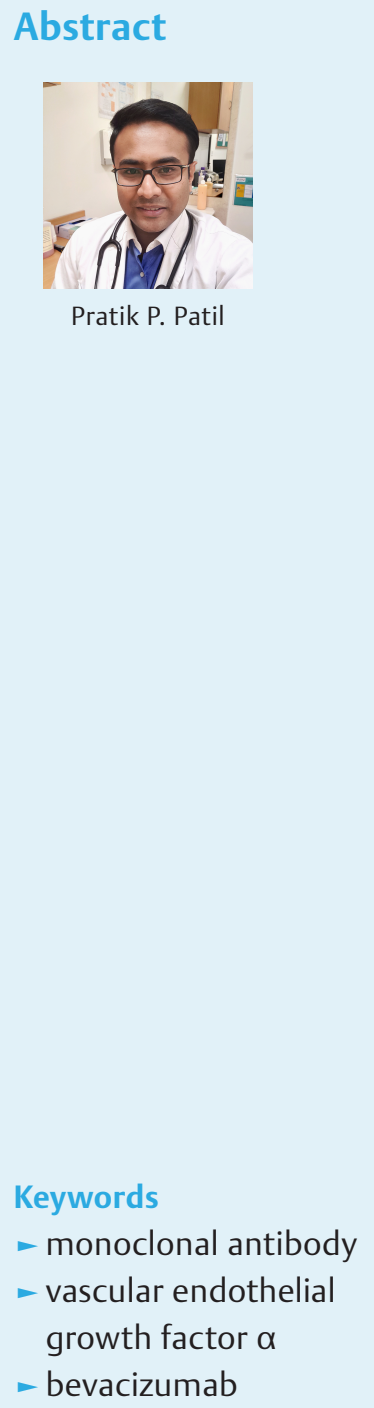

Background Bevacizumab, a humanized monoclonal antibody, known to block the binding of all known vascular endothelial growth factor-A isomers to their receptors, is used in solid cancers, especially in advanced settings where its role is proven to be stronger than localized stages. Furthermore, various studies have suggested that adding bevacizumab to first-line standard therapy in advanced solid cancers, such as colorectal cancer, lung cancer, ovarian cancer, renal cancer, and breast cancer, significantly prolongs progression-free survival, overall survival, and response rates. However, this ability is limited and variable in cancer subtype. The toxicity profile of bevacizumab is outspread, ranging from mild gastrointestinal side effects, proteinuria to life-threatening hemorrhagic tendency, ischemic thromboembolism, and intestinal perforation. However, it has never been studied in Indian subset of patients till date.

Materials and Methods We performed an institutional retrospective study of 41 patients with a pathologically proven ovarian, colorectal, lung, mesothelioma, melanoma, round cell tumors, and GBMs who received bevacizumab $(2.5 \mathrm{mg} / \mathrm{kg} /$ week [ $5 \mathrm{mg} / \mathrm{kg}$ every 2 weeks or $7.5 \mathrm{mg} / \mathrm{kg}$ every 3 weeks]) with or without chemotherapy, between January 2016 and January 2019 at our center in North India.

Results Forty-one patients, including 12 (29) advanced ovarian cancer, 12 (29) colon cancer, 10 (24) rectal cancer, 1 (2) appendicular cancer, 1 (2) mesothelioma, 1 (2) melanoma, 1 (2) desmoplastic round cell tumor, and 3 (7) GBM, were treated with bevacizumab. The incidence of arterial thrombus and hemorrhage was 2 and 10\%, respectively, whereas venous thrombus and fistula were not seen and not related to age. No fatal adverse event was recorded. The global incidence of severe (grade 3/4) arterial hypertension (HTN) was 49\%. It was safely managed in all cases, and no grade 4 (life-threatening complication) occurred. The incidence of severe HTN was significantly higher in elderly patients than in younger ones (72 vs. $40 \%$ ), proteinuria was found to be more frequent in the younger age group as compared with older age group (7 vs. $3 \%)$. Also to note, the incidence of congestive heart failure and subacute intestinal obstruction was found in $5 \%$ of patients, wherein all four patients belonged to the older subgroup. Furthermore, Grade 3 hypersensitivity reaction was found in one patient in the younger subgroup which warranted immediate termination of bevacizumab.
DOI https://doi.org/10.1055/s-0041-1729445 ISSN 2278-330X

How to cite this article: Patil PP, Rangaraju RR, Abbas W, Garg S. Real-World Experience in Toxicity with Bevacizumab in Indian Cancer Patients. South Asian J Cancer 2021;10(2):131-134.
(C) 2021. MedIntel Services Pvt Ltd.

MedIntel Services PvtLtd.. This is an open access article published by Thieme under the terms of the CreativeCommons Attribution-NonDerivative-NonCommercial-License, permitting copying and reproduction so long as the original work is given appropriate credit. Contents may not be used for commercial purposes, or adapted, remixed, transformed or built upon. (https://creativecommons.org/licenses/by-nc-nd/4.0/). Thieme Medical and Scientific Publishers Private Ltd A-12, Second Floor, Sector -2, NOIDA -201301, India 


\section{Introduction}

Formation and growth of tumor in the body are induced by the appearance of new blood vessel that increases the vascularity and blood supply to the tumor. This process of vascular angiogenesis harbors tumorigenesis and increases its metastatic potential. Vascular endothelial growth factor (VEGF) is a potent factor responsible for this effect and increases tumorigenesis, as well as its metastatic spread. Targeting this factor has been researched in the recent past and found to be a potent proangiogenic factor that appears in various solid cancers. Researchers have proven various ways to inhibit this factor through VEGF ligands, small-molecule inhibitors of VEGF tyrosine kinase receptor activity, and molecules that bind and inhibit the VEGF receptors. ${ }^{1}$

Bevacizumab, a humanized monoclonal antibody, is known to block the binding of all known VEGF-A isomers to their receptors. It has been studied in combination, as well as a single-agent suppressing tumor angiogenesis and growth in animal models. ${ }^{1}$ This data brought the agent bevacizumab for the treatment of solid cancers, especially in advanced settings where its role is proven to be stronger than localized stages. Various studies have suggested that adding bevacizumab to first-line standard therapy in advanced solid cancers, such as colorectal cancer, lung cancer, ovarian cancer, renal cancer, and breast cancer, significantly prolongs progression-free survival, overall survival, and response rates; however, this ability is limited and variable in cancer subtype. ${ }^{2}$ Unfortunately, there is no proven biomarker available for its definitive use and the near future awaits it.

Bevacizumab when used with the Food and Drug Administration approved dose of 7.5 to $15 \mathrm{mg} / \mathrm{kg}$ is associated with adverse events (AEs) ranging from grade 1 of 2 events, such as neutropenia (76\%), thrombocytopenia (49\%), anemia (28\%), asthenia (12\%), vomiting (9\%), and hypertension (HTN; $2 \%)$, to severe events such as bleeding (4\%), proteinuria ( $2 \%)$, gastrointestinal (GI) perforation $(<1 \%)$, ischemic events $(2 \%)$, thromboembolic episodes $(7 \%)$, and also very rarely fatal pulmonary hemorrhage $(<1 \%)^{3-5}$ Furthermore, the rate of treatment discontinuations as a result of AEs is more with chemo-bevacizumab combination arm, 26 and $30 \%$ of patients in the low- and high-dose bevacizumab arms, respectively. Rates of death as a result of AEs, regardless of causality, are in the range of 4 to $5 \%$ for both the low- and high-dose patients. ${ }^{6,7}$

\section{Materials and Methods}

We performed an institutional retrospective study of patients with a pathologically proven ovarian, colorectal, lung, mesothelioma, melanoma, round cell tumors, and GBMs who received bevacizumab with or without chemotherapy (CT), between January 2016 and January 2019, at our Center in Max Super Speciality Hospital, Shalimar Bagh, New Delhi, India. All cases were identified using electronic files of the hospital system. At this center, the use of bevacizumab was not restricted to the patient's age; however, it was avoided in patients with uncontrolled and/or untreated HTN or experiencing arterial thrombosis or severe bleeding in the year before treatment. It was also avoided in those considered to present a high risk of perforation or fistula (recent intestinal occlusion, permanent abdominal pain, personal history of GI perforation or fistula, and evidence of bowel involvement on physical examination or computerized tomography scan). All patients who were deemed fit for bevacizumab administration received a dosage intensity of $2.5 \mathrm{mg} / \mathrm{kg} /$ week $(5 \mathrm{mg} / \mathrm{kg}$ in every 2 weeks or $7.5 \mathrm{mg} / \mathrm{kg}$ in every 3 weeks) of this drug.

The primary objective here was to assess the incidence of potentially life-threatening AEs of bevacizumab according to the patient's age. The following events were, hence, considered in the assessment: severe HTN, proteinuria, arterial and venous thrombosis, bleeding, and fistula or intestinal perforation. Severe HTN was defined as the National Cancer Institute Common Terminology Criteria for Adverse Events version 4 (CTCAE v4.0) grade 3 (systolic blood pressure [BP] Q of $160 \mathrm{~mm} \mathrm{Hg}$ or diastolic BP Q of $100 \mathrm{~mm} \mathrm{Hg}$ ) or more than one drug or more intensive therapy than previously used or grade 4 (life-threatening consequences). Routine follow-up of BP was performed at home every day between the first and second infusions and then at every week. The CTCAE v4.0 was used to assess AEs. Proteinuria was assessed before each infusion by dipstick. Positive results were confirmed by 24-hour sample collection.

\section{Results}

Forty-one patients, including 12 (29) advanced ovarian, 12 (29) colon cancer, 10 (24) rectal cancer, 1 (2) appendicular cancer, 1 (2) mesothelioma, 1 (2) melanoma, 1 (2) desmoplastic round cell tumor, and 3 (7) GBM, treated with bevacizumab between January 2016 and January 2019 were included in this analysis. Patients' characteristics are summarized in - Table 1.

The median age at first infusion of bevacizumab was 57.5 years, and 11 patients (27) were older than 65 years. The majority of patients (29 [71]) had received concomitant CT with bevacizumab. At baseline, controlled arterial HTN was more frequently observed in younger individuals, 8 of 30 (27). The median number of bevacizumab infusions was, however, slightly higher in younger patients but with no significant difference.

As shown in - Table 2, the incidence of arterial thrombus and hemorrhage was 2 and 10\%, respectively, whereas venous thrombus and fistula were not seen and not related to age. No fatal AE was recorded. The global incidence of severe (grade $3 / 4$ ) arterial HTN was $49 \%$. It was safely managed in all cases, and no grade 4 (life-threatening complication) occurred. The incidence of severe HTN was significantly higher in elderly patients than in younger ones (72 vs. $40 \%$ ), proteinuria was found to be more frequent in the younger age group as compared with older age group ( 7 vs. $3 \%$ ). Also to note, the incidence of congestive heart failure and subacute intestinal obstruction was found in $5 \%$ of patients, wherein all four patients belonged to the older subgroup. Furthermore, grade 3 hypersensitivity reaction was found in one patient in the younger subgroup which warranted immediate termination of bevacizumab. 
Table 1 Baseline patient characteristics

\begin{tabular}{|l|l|l|l|}
\hline Number of patients & $\begin{array}{l}\text { Overall population } \\
(\boldsymbol{n}=\mathbf{4 1})\end{array}$ & $\begin{array}{l}\text { Patients }<65 \text { years } \\
(\boldsymbol{n}=30)\end{array}$ & $\begin{array}{l}\text { Patients }>65 \text { years } \\
(\boldsymbol{n}=11)\end{array}$ \\
\hline Median age (y) & 57.5 & $11(37)$ & 69 \\
\hline Concomitant CT $n(\%)$ & $29(71)$ & 2 & $10(90)$ \\
\hline $\begin{array}{l}\text { Median number of CT lines } \\
\text { before bevacizumab }\end{array}$ & 2 & 11 & 3 \\
\hline $\begin{array}{l}\text { Median number of bevacizumab } \\
\text { infusions }\end{array}$ & 9 & $4(13)$ & 8 \\
\hline Bevacizumab as a first line $n(\%)$ & $6(15)$ & $8(27)$ & $2(18)$ \\
\hline Baseline arterial HTN $n(\%)$ & $12(29)$ & $4(36)$ \\
\hline
\end{tabular}

Abbreviations: CT, chemotherapy; HTN, hypertension.

Table 2 Incidence of adverse vascular events (all grades) induced by bevacizumab in relation to age

\begin{tabular}{|l|l|l|l|}
\hline Number of patients & Overall population $(\boldsymbol{n}=\mathbf{4 1})$ & Patients $<65$ years $(\boldsymbol{n}=\mathbf{3 0})$ & Patients $>65$ years $(\boldsymbol{n}=\mathbf{1 1})$ \\
\hline $\begin{array}{l}\text { Median number of bevacizumab } \\
\text { infusions }\end{array}$ & 9 & 11 & 8 \\
\hline Arterial thrombosis & $1(2)$ & $1(3)$ & - \\
\hline Venous thrombosis & - & - & - \\
\hline Hemorrhage & $4(10)$ & $1(3)$ & $3(27)$ \\
\hline Grade 3/4 arterial HTN & $20(49)$ & $12(40)$ & $8(72)$ \\
\hline Proteinuria & $3(7)$ & $1(3)$ & $2(18)$ \\
\hline Congestive heart failure & $2(5)$ & - & $2(18)$ \\
\hline Subacute intestinal obstruction & $2(5)$ & - & $2(18)$ \\
\hline Hypotension & $1(2)$ & $1(3)$ & - \\
\hline $\begin{array}{l}\text { Grade 3/4 hypersensitivity } \\
\text { reaction }\end{array}$ & $1(2)$ & $1(3)$ & - \\
\hline
\end{tabular}

Abbreviation: HTN, hypertension.

Table 3 Incidence of severe arterial hypertension induced by bevacizumab in relation to baseline hypertension

\begin{tabular}{|l|l|}
\hline & $\begin{array}{l}\text { Severe grade } 3 / 4 \text { HTN } \\
\text { induced by bevacizumab } \\
\boldsymbol{n}(\%)\end{array}$ \\
\hline Baseline HTN yes $(n=12)$ & $20(49)$ \\
\hline Baseline HTN no $(n=29)$ & $8(27)$ \\
\hline $\begin{array}{l}\text { Baseline HTN age }>65 \text { years } \\
(n=4)\end{array}$ & $8(72)$ \\
\hline $\begin{array}{l}\text { Baseline HTN age }<65 \text { years } \\
(n=8)\end{array}$ & $12(40)$ \\
\hline $\begin{array}{l}\text { Baseline no HTN age }>65 \text { years } \\
(n=7)\end{array}$ & $6(85)$ \\
\hline $\begin{array}{l}\text { Baseline no HTN age }<65 \text { years } \\
(n=22)\end{array}$ & $2(9)$ \\
\hline
\end{tabular}

Abbreviation: HTN, hypertension.

As suggested by - Table 3, patient who had baseline HTN before starting the therapy with bevacizumab, 12 (29\%) rose to 20 (49\%) during treatment with the drug of which $72 \%$ belonged to the older subgroup and $40 \%$ belonged to the younger subgroup. Furthermore, among the baseline normotensive patients off treatment, eight (27\%) developed grade 3 of 4 HTN which could be bevacizumab related. Of these patients, $85 \%$ belonged to the older subgroup, whereas only $9 \%$ belonged to the younger subgroup.

\section{Discussion}

This study is the first to report real-life experience data with the use of bevacizumab in various solid organ cancers in the Indian subset of patients. The overall incidence of venous thromboembolism and arterial thromboembolism was rare, in line with previous clinical trials. ${ }^{8-10}$ The data suggest that the older patients who did not experience a thrombotic episode in the year before treatment are not at more risk during bevacizumab treatment than younger patients. In contrast, the incidence of hemorrhage was more in our patients, especially in the older subgroup, as compared with the historically quoted incidences. ${ }^{11,12}$ We did not observe any event of intestinal perforation or fistula, which is again in contrast to a phase-2 study of ovarian cancer in which it was found in $11.4 \%$ of cases with bevacizumab therapy as a single agent when heavily pretreated by other agents. ${ }^{6}$ Also to note, a history of inflammatory bowel disease, previous surgeries 
on bowel mucosa, and bowel obstruction were found to be associated risk factors for bevacizumab-induced intestinal perforation or fistula. ${ }^{13}$ Hence, careful selection of patients can reduce the toxicity, as well as complications.

The incidence of bevacizumab-induced HTN was found be to significantly higher in our study patients as compared with the large randomized trials. ${ }^{8-10}$ Furthermore, this data suggest that carefully selecting patients on the basis of pretherapy findings could prevent therapy-induced side effects and complications. However, we could identify two risk factors for bevacizumab-induced HTN: older patients and baseline-controlled HTN. Home monitoring of BP had proved that with all the VEGF-inhibiting agents, including bevacizumab, there is a sudden surge of BP after the first few cycles of the drug..$^{14}$ It can, therefore, be said that surges of BP to grade 3 of 4 level can happen in patients who are hypertensive before starting on therapy and receiving antihypertensive medications. Baseline HTN is in close relation with the age of the patient, but the above said two parameters are independently associated with severe HTN.

There are very less data on the safety of bevacizumab in solid cancers in the elderly population worldwide and almost no data from Indian/Asian subset of patients. In advanced colon cancer trial, BriTE, it was said that increased incidence of thromboembolic events occurred in patients treated with bevacizumab but when adjusted with the history and risk of thromboembolism, it was not a significant finding, ${ }^{15}$ supporting the same findings as in our data where the risk of venous thromboembolism is almost nil.

\section{Conclusion}

Age itself does not appear to be a contraindication for the use of bevacizumab. A holistic approach considering age, history of physical inactivity, risk of HTN, baselines HTN, and other surgical history should be taken into, and multidisciplinary cardiovascular assessment should be recommended before starting an antiangiogenic treatment. Our experience suggests that with a well-adjusted risk assessment and a careful follow-up of HTN, bevacizumab could be used safely in older patients as well.

\section{Funding}

Nil.

\section{Authors' Contributions}

All contributors have equally participated and shared in terms of concepts, intellectual content, design, literature search, experimental studies, data acquisition, data analysis, statistical analysis, manuscript preparation, editing, and review.
Conflicts of Interest

There are no conflicts of interest.

\section{References}

1 Pañares RL, Garcia AA. Bevacizumab in the management of solid tumors. Expert Rev Anticancer Ther 2007;7(4):433-445

2 Roviello G, Bachelot T, Hudis CA, et al. The role of bevacizumab in solid tumours: a literature based meta-analysis of randomised trials. Eur J Cancer 2017;75:245-258

3 Reck M, von Pawel J, Zatloukal P, et al. Phase III trial of cisplatin plus gemcitabine with either placebo or bevacizumab as firstline therapy for nonsquamous non-small-cell lung cancer: AVAil. J Clin Oncol 2009;27(8):1227-1234

4 Tlemsani C, Mir O, Boudou-Rouquette P, et al. Posterior reversible encephalopathy syndrome induced by anti-VEGF agents. Target Oncol 2011;6(4):253-258

5 Huang $\mathrm{H}$, Zheng Y, Zhu J, Zhang J, Chen $\mathrm{H}$, Chen X. An updated meta-analysis of fatal adverse events caused by bevacizumab therapy in cancer patients. PLoS One 2014;9(3):e89960

6 Cannistra SA, Matulonis UA, Penson RT, et al. Phase II study of bevacizumab in patients with platinum-resistant ovarian cancer or peritoneal serous cancer. J Clin Oncol 2007;25(33):5180-5186

7 Talarico L, Chen G, Pazdur R. Enrollment of elderly patients in clinical trials for cancer drug registration: a 7-year experience by the US Food and Drug Administration. J Clin Oncol 2004;22(22):4626-4631

8 Burger RA, Brady MF, Bookman MA, et al; Gynecologic Oncology Group. Incorporation of bevacizumab in the primary treatment of ovarian cancer. N Engl J Med 2011;365(26):2473-2483

9 Perren TJ, Swart AM, Pfisterer J, et al; ICON7 Investigators. A phase 3 trial of bevacizumab in ovarian cancer. N Engl J Med 2011;365(26):2484-2496

10 Aghajanian C, Blank SV, Goff BA, et al. OCEANS: a randomized double-blind, placebo-controlled phase III trial of chemotherapy with or without bevacizumab in patients with platinum-sensitive recurrent epithelial ovarian, primary peritoneal, or fallopian tube cancer. J Clin Oncol 2012;30(17):2039-2045

11 Pujade-Lauraine E, Hilpert F, Weber B, et al. Bevacizumab combined withchemotherapy for platinum-resistantrecurrentovarian cancer: The AURELIA open-label randomized phase III trial. J Clin Oncol 2014;32(13):1302-1308

12 Emile G, Chauvenet L, Tigaud JM. Chidiac J, Pujade Lauraine $\mathrm{E}$, Alexandre J. A clinical experience of single agent bevacizumab in relapsing ovarian cancer. Gynecol Oncol 2013;129(3):459-462

13 Burger RA, Brady MF, Bookman MA, et al. Risk factors for Gl adverse events in a phase III randomized trial of bevacizumab in first-line therapy of advanced ovarian cancer: A Gynecologic Oncology Group Study. J Clin Oncol 2014;32(12):1210-1217

14 Azizi M, Chedid A, Oudard S. Home blood-pressure monitoring in patients receiving sunitinib. NEngl J Med 2008;358(1):95-97

15 Kozloff MF, Berlin J, Flynn PJ, et al. Clinical outcomes in elderly patients with metastatic colorectal cancer receiving bevacizumab and chemotherapy: results from the BRiTE observational cohort study. Oncology 2010;78(5,6):329-339 